\title{
JUSTIFYING ONESELF*
}

\author{
MARK PIPER \\ James Madison University
}

\begin{abstract}
At present, the activity of justifying oneself is mostly discussed in psychology, where it is typically viewed as a negative or at least regrettable activity involving changing one's attitudes, beliefs, and feelings in order to minimize psychological threats arising from cognitive dissonance. Yet there is conceptual space, even a need, for an analysis of justifying oneself that is more content-neutral in nature. In this paper I provide such an analysis. Along the way I also briefly canvass some of the empirical work on selfjustification in psychology and gesture towards issues surrounding the normative significance of the practice of justifying oneself.
\end{abstract}

Keywords: justification, self-justification, self-defense, commitment, internal justification, external justification, dialectical interaction

\section{Introduction}

We attempt to justify ourselves constantly. Sometimes we do this casually, sometimes earnestly, sometimes desperately. We justify ourselves in response to others' challenges to our commitments and in the face of our own self-doubts. From moral exemplars to ordinary folks to flagellants, everyone feels the need to justify themselves in one way or another, perhaps more often than we would think. Justifying oneself is an ineliminable, important, even dominating feature of our lives.

But what exactly is involved in engaging in the act of justifying oneself? Note that this question is distinct from the exhaustively discussed epistemological question of what constitutes a good justification for a claim. The epistemological question is fundamentally normative; it concerns how justification ought to be done if one wishes to establish some kind of claim. My concern is to provide a descriptive conceptual 
analysis of the act of justifying oneself, which may or may not satisfy epistemic ideals. Note also that my concern is separate from epistemological inquiries into statements, propositions, or beliefs that are said to be self-justifying in the sense of possessing epistemic warrant without reliance on further statements, propositions, or beliefs serving as justificatory supports. By contrast, my interest is in providing an account of the activity of attempting to justify oneself. My analysis is thus much closer to work in moral psychology than epistemology. ${ }^{1}$

At present, the activity of justifying oneself is mostly discussed in psychology, where it is typically viewed as a negative or at least regrettable activity involving changing one's attitudes, beliefs, and feelings in order to minimize psychological threats arising from cognitive dissonance (Burkley and Blanton 2005). ${ }^{2}$ Yet there is conceptual space, even a need, for a conception of justifying oneself that is more contentneutral in nature. Providing such an analysis could also be useful by clarifying its likely effects, and thereby facilitating insights regarding whether possessing a robust habit of justifying oneself tends to be productive of more benefit or harm. Although defending a normative judgment on that score would render my work more compelling in terms of practical relevance, my aspirations here are considerably more modest. I seek only to provide a theoretical analysis of the practice of justifying oneself, a practice with which we are all familiar from our daily lives. Along the way I briefly canvass some of the empirical work on selfjustification in psychology, and I gesture towards issues surrounding the normative significance of justifying oneself, but my primary aim is to explore its conceptual contours. My hope is to provide an analysis that can be useful in relation to a variety of further theoretical and normative inquiries relating to this important and ubiquitous activity.

\section{Empirical studies}

The psychological literature is fairly united in holding the act of justifying oneself to be a negative or unfortunate activity. ${ }^{3}$ This may

\footnotetext{
${ }^{1}$ The emphasis upon dialogical justificatory practice renders the present work similar in certain respects to the study of dialectical interaction, which is importantly separate from epistemology. See Rescorla (2009) for more details.
}

2 Researchers in psychology distinguish between internal self-justification strategies, which involve changing one's perception of the problem behavior (by, for example, changing one's attitude towards it, trivializing it, or denying that the behavior has negative consequences) and external self-justification strategies, which involve claiming that one is not responsible for the unwanted behavior in question. See Chigona, Chigona, Ngqokelela, and Mpofu (2009).

${ }^{3}$ A similar, negative conception of justifying oneself can also be found amongst some philosophers. See e.g. Lang (2002) and D'Cruz (2015). 
simply be entailed by the particular conceptions employed by psychologists, but their findings are worth mentioning insofar as they provide background for the present study and indicate the predominantly negative view amongst scholars working on the topic.

A 2008 study suggests that there is an important correlation between providing a self-serving justification and stretching the truth (Mazar, Amir, and Ariely 2008). Another study supports the claim that the prevalence of justifying oneself, understood as making excuses for negatively viewed behavior, is negatively correlated with self-esteem: the more self-esteem one possesses, the less likely one is to engage in justifying onself, and vice versa (Holland, Meertens, and van Vugt 2002). Jonathan Lowell has argued that acts of self-justification induced by cognitive dissonance can create "an amplifying feedback loop and downward spiral of immoral behavior" amongst business managers (Lowell 2012, 17). A 2014 study claims that processes of justifying oneself contribute to failures in self-regulation or autonomy (de Witt Huberts, Evers, and de Ridder 2014). According to a more recent study, increased self-justification by perpetrators of sexual aggression is a significant predictor of further sexual aggression over a one-year followup period (Wegner, Abbey, Pierce, Pegram, and Woerner 2015; see also Scully and Marolla 1984). ${ }^{4}$ Another recent study argues that justifying oneself before and after intentional ethical violations tends to enable people to do wrong while feeling moral (Shalvi, Gino, Barkan, and Ayal 2015). ${ }^{5}$

Not all psychologists think that justifying oneself, understood here as the giving of excuses for one's behavior, is always a bad thing. C.R. Snyder and R.L. Higgins, for example, have argued that this activity can have benefits insofar as it conduces to more successful reality negotiation (Snyder and Higgins 1988). See also Kivetz and Zheng 2006.

The last citations notwithstanding, most psychologists seem to view justifying oneself as a regrettable activity, something done primarily for the sake of self-protection in the face of potentially disturbing cognitive tensions. On this view, engaging in justifying oneself goes hand in hand with some degree of closedmindedness. People who engage in justifying themselves are trying to protect the integrity of their belief systems, to avoid internal conflicts and thereby render their mental lives smooth, satisfying, and unassailable, even if that means blocking out good

\footnotetext{
${ }^{4}$ It is instructive to note that these authors understand 'self-justification' as "making excuses for one's discrepant behavior." Given this definition, perhaps their findings aren't particularly surprising.

5 According to this study, 'self-justification' is defined as 'the process of providing reasons for questionable behaviors and making them appear less unethical." (125) For a related study, see Pittarello, Leib, Gordon-Hecker, and Shalvi (2015).
} 
evidence, reasonable concerns, and the like. All too often, many psychologists worry, justifying oneself leads to the intellectual equivalent of stopping up one's ears to new ideas and perspectives until one can safely sort out why one is in the right, at least to one's satisfaction. From this point of view, justifying oneself certainly does seem to be a regrettable activity.

While it cannot be denied that justifying oneself can be prompted by selfserving reasons of this sort, it is far from clear that the activity as a whole deserves such general condemnation. I wish to argue, in fact, that the activity of justifying oneself in general ought not to be conceptually pigeonholed in this way. The analysis I defend below certainly makes room for unfortunate instances of justifying oneself, but it does not limit itself to them.

\section{Justifying oneself}

Justifying oneself is the act of defending, verbally, in writing, or in thought, the actions, values, goals, attitudes, dispositions, loyalties, intuitions, and the like (henceforth 'commitments') that one holds as part of one's identity in response to an external or internal challenge, in the hopes, at best, of bringing the challenger to accept the commitments they have challenged, or, at the least, of resulting in a conviction in the one justifying that the demands of justification have been met and hence that no further justification is necessary. Eight aspects of this analysis require further comment. In what follows, 'justifying oneself' should be understood as shorthand for 'the act of justifying oneself'.

(1) Notice first that justifying oneself encompasses attempts to justify a person's commitments in the broadest sense, not only the person's personality. While justifying oneself may seem to relate only to general attacks on one's character and the like, this is too narrow. Our commitments are parts of who we are. When we defend parts of ourselves that are sincerely bound up in our identities - our ideas, suggestions, values, attitudes, actions, nonactions, interpretations, traits, thoughts, policies, goals, and so on - we are justifying ourselves.

(2) Justifying oneself is primarily an act of defense. This is important insofar as it establishes that justifying oneself conceptually requires a prior moment of challenge. Yet the challenge shouldn't necessarily be conceived as an attack. Although some challenges are robust or offensive enough to warrant that description, many challenges are little more than passing doubts or friendly questions that potentially call for a justificatory response.

(3) Contrary to the dominant view amongst psychologists, the act of defense that characterizes justifying oneself needn't be motivated by the desire to protect the integrity of one's belief system. Justifying oneself 
needn't always be blindly or closedmindedly self-protective. The resistance constitutive of justifying oneself may just as easily be motivated by the correct conviction that one has excellent reasons to have the commitments one has. In short, justifying oneself can be and often is prompted by a correct commitment to reason rather than by a desire to protect oneself at all costs in order to avoid cognitive dissonance.

(4) In a similar vein, justifying oneself does not imply closedmindedness. It may be thought that justifying oneself implies that the one engaging in it has already made up her mind on the issue. After all, why would one justify one's commitments unless one thought that those commitments are correct or appropriate? But while some cases of justifying oneself may involve closedmindedness, it is not difficult to imagine cases in which a person engages in justifying oneself but remains open to the possibility that he is mistaken. People often claim to have beliefs but be humble about them. While some people merely say this but don't mean it, many people say it and mean it. Many cases of justifying oneself can thus be viewed as provisional in the sense that the one engaging in the justification thinks that it is warranted at the time or is at least committed to pushing the warrant at the moment of justification, but remains open to the possibility that counterevidence might lead one to a change of mind, possibly even soon after providing the justification. Reflection on everyday experience suggests that this is not at all uncommon.

(5) Justifying oneself only takes place in response to challenges to our sincerely-held commitments. By this I mean commitments that we consider important in some way for our identity or person, commitments that are typically bound up with emotional attachments and the threat of personal loss of some kind. Challenges that do not touch a 'self'-nerve in this way might call for response of some kind, but it is misleading to characterize them as acts of justifying oneself. If I suggest that we should paint the wall blue, but I don't really care, and you say that we should paint it green, I am not thereby pulled into an act of justifying myself; I can shrug and agree without any feeling of personal loss. If, however, I am sincerely attached to the idea of painting the wall blue, for whatever reason, and you challenge this idea, then justifying myself is on the table again. Obviously there will be grey areas when it comes to distinguishing between challenges that do not call for justifying oneself and those that do, but I will not attempt to defend criteria by which such muddy cases can be adjudicated.

(6) A challenge needn't be given by an external source. It could be provided by oneself and for oneself in the course of reflecting upon one's commitments. Moreover, in cases of internal critique, the challenge needn't be consciously formulated. On the plausible assumption, which I will not defend here, that subconscious challenges exist and influence us, it is possible that a person may feel compelled to justify her commitments to herself out of an inchoate apprehension that they stand in need of 
further support or validation.

(7) As mentioned, an act of justifying oneself has a purpose: at best, to bring the challenger to accept the challenged commitments, or, at the least, to bring the one attempting the justification to the belief that the challenged commitments have been defended well enough such that no further justification is necessary. The latter goal is in some ways the more primary; for even if a person engaged in justifying herself fails to convince her objector, she will have successfully performed an act of justifying herself if she considers her defense to have been adequate. Justifying oneself thus inherently involves providing a defensive response to a challenge of some kind in the hope of establishing, for oneself or others, that one's commitments are acceptable in some sense. This is why there are close relations between justifying oneself and the feeling in the one challenged of vindication - the feeling of, 'on the contrary, this is acceptable!'

The word 'acceptable' may strike some as unhelpfully imprecise, but I have chosen it with care for the reason that one may engage in justifying oneself with the goal of eliciting a variety of different reactions of acceptance from one's challenger. These reactions can be viewed as lying on a spectrum characterized by differing levels of acceptability. Starting from the highest levels and working downwards, the scale would look something like this:

\section{Faultless}

Excellent

\section{Good}

\section{Reasonable}

Satisfactory

Tolerable

No worse than anything else

Not entirely daft

The hoped-for level of acceptance in any given situation will depend upon the particulars of the situation. If I am defending a paper at a conference and one of my arguments is challenged, I may attempt to justify my commitments with such strength and clarity that my objector comes to realize that his challenge was entirely inadequate for some reason, such as failing to note a caveat I had made, failing to see a relation of implication, failing to see that his argument is based upon false premises, and the like. In this case, assuming my defense is sound, my objector may withdraw his objection and judge my justification to be faultless or excellent. A student justifying her decision to go to Panama City for spring break in response to his parents' worries about his safety would likely not expect such success; he might hope to justify his 
decision in such a way that his parents find his justification good or reasonable or satisfactory or perhaps simply tolerable. A president called by a leader of the political opposition to defend her foreign policy decisions on the grounds that they will lead to catastrophe may, in her act of justification, only hope to establish in her objector's mind, or in her own, if she still entertains doubts, that the policy is no worse than any other feasible policy, or that the policy, even if imperfect in some ways, is not entirely daft. ${ }^{6}$

(8) Note that the kind of acceptance discussed above is not to be understood as necessarily satisfying epistemic desiderata. The goal of epistemic justification is truth, and epistemic demands may be satisfied without any psychological acceptance taking place. Successful justification of oneself as here conceived amounts to a form of psychological closure: even if only for the moment, the challenger is silenced or, at the very least, the one justifying oneself is satisfied that the demands of justification have been met. Unfortunately, from an epistemic point of view at least, this can happen with or without rational reasons in support of that experience of closure. Successful attempts to justify oneself, in the broad sense under discussion here, can thus include or not include actual epistemic success. For this reason, an act of justifying oneself should not only be conceived as giving a well-structured argument with supporting evidence in response to a challenge. There are many ways to attempt to defend a commitment, some of which have better rational credentials than others, but all of which can function to put lingering doubts to rest, if only for a time, in order to achieve the desired acceptance. Well-structured arguments can certainly play this role, but explanations, clarifications, consideration of new or extenuating factors, and even rhetorical tricks can be employed in the service of this end. Thus we can say in one case that although someone justified a belief to her satisfaction in the sense discussed above, her justification was not in fact rational; but we could just as well say in another case that someone not only justified a belief to his or another's satisfaction, but did so in a way that satisfies rational desiderata as well. ${ }^{7}$

\section{Relation to associated theoretical issues}

(1) Justifying oneself as understood here is entirely normatively neutral regarding the content that it seeks to justify. There are no normative constraints upon the objects of justification. This is why some cases of

\footnotetext{
${ }^{6}$ My thanks to an anonymous reviewer for the European Journal of Analytic Philosophy for suggesting this further level of acceptance.

${ }^{7}$ I would like to thank an anonymous reviewer for the European Journal of Analytic Philosophy for pressing me to elaborate on these points.
} 
justifying oneself will be quite faultless in all normative, epistemic, or logical respects. Other cases will involve error in one or more of these respects.

(2) Cases of positive evaluation of oneself without relation to a prior moment of challenge do not count as justifying oneself. If, absent any form of challenge to one of my commitments, I reflect upon it and find it good in some way, I am not engaged in an act of justifying myself. When I reflectively review and applaud my commitments without prior prompting by any kind of challenge, I could be said to be instead engaged in an act of endorsement. Unlike justifying oneself, endorsement without prior challenge is entirely coherent. Obviously there are muddy waters here. Are we sure that there are no lurking subconscious challengeprompts? Are we sure that we are not reflectively reviewing our commitments because of a now-forgotten challenge sourced in a past conversation or reading? Often it will be hard or even impossible to tell. But on the assumption that no such challenges are present, yet an act of endorsement takes place, the endorsement should not be confused with an act of justifying oneself.

(3) Justifying oneself has conceptual similarities to giving excuses, but there is at least one important difference. An excuse is given by or on behalf of a person in response to a claim of wrongful action or inaction in order to abrogate responsibility for that action or inaction. Excuses are thus inherently linked to evading or repudiating responsibility for something. By contrast, it is entirely possible to justify oneself without seeking to annual responsibility for one's commitments or actions. We find a good example of this in Plato's Crito.

(4) Justifying oneself has conceptual links to adaptive preferences, but they are not identical. Adaptive preferences are preferences for future things, where those preferences have been formed in response to oppressive or unfavorable past conditions (Elster 1989; Christman 2014; Stoljar 2014). Justifying oneself involves justifying existing commitments, which need not have been formed by oppressive or unfavorable past conditions, but which have been called into question by some form of prior challenge. Many cases of justifying oneself are entirely appropriate, benign, and reasonable. Many cases of justifying oneself have superb rational credentials and take place without the causal history distinctive of the formation of adaptive preferences. Of course, some cases of justifying oneself are closely related to adaptive preference formation. I may be challenged on an adaptively-formed, sincerely held commitment and thereby called to engage in an act of justifying myself. Yet I can just as well have adaptive preferences that are never challenged, or I can have adaptive preferences that are challenged but are not sincerely held by me, or I can attempt to justify commitments that are not adaptive preferences. 
(5) Justifying oneself is also conceptually close to wishful thinking. Wishful thinking is characterized by forming beliefs and making decisions based upon what we would like to be true or false rather than upon what evidence or careful argumentation supports. Wishful thinking, which constitutes an informal logical fallacy when it is used to defend beliefs, may be a way in which to engage in justifying oneself, admittedly a poor one from a rational perspective, and perhaps this is not altogether uncommon. But it is quite possible to engage in justifying oneself without using wishful thinking methods, and it is also possible to engage in wishful thinking when forming beliefs or making decisions in a way that doesn't involve justifying oneself. This would happen when there was no prior challenge to a person's sincerely-held commitments, for example. Other differences are notable as well. Some cases of justifying oneself can be epistemically respectable, whereas justification by wishful thinking is always fallacious. And while both justifying oneself and wishful thinking can be prompted by a perceived challenge to one's commitments, the threat in the wishful thinking case doesn't have to be a challenge. It could simply be prompted by the unfortunate circumstances in which one finds oneself (e.g. the grapes are out of reach).

(6) We can distinguish among self-justifying acts, habits, and people. Self-justifying acts are one-off attempts at justifying oneself. A selfjustifying person is a person who has a regular and wide-ranging habit of engaging in self-justifying acts. Self-justifying people needn't be understood as always and everywhere engaging in this activity, only regularly and widely. Someone who lacks this habit may certainly engage in acts of justifying herself on this or that occasion, provided that such acts are not grounded in an entrenched, pervasive disposition. ${ }^{8}$ Attempting to provide criteria to underwrite a sharp distinction between the two types of person would take us too far afield, and would likely be fruitless anyway.

(7) Robustly self-justifying people have a habit of attempting to justify most of their commitments most of the time in response to a wide range of perceived challenges, internal and external, imagined and real. Such a habit can have both beneficial and harmful effects. Although I will not provide arguments for the following claims, I would speculate that the likely positive effects of a habit of justifying oneself would include, in different circumstances and for different characters, (a) a sense of selfesteem/self-love/self-worth, (b) a sense of belonging, (c) self-knowledge/ self-awareness, (d) autonomy, (e) self-assurance/self-confidence, (f) rightful self-promotion, ( $\mathrm{g}$ ) a sense of contentment, (h) a habit of selfscrutiny, (i) taking oneself seriously, and (j) taking others' views seriously. The likely negative effects would include, in different

\footnotetext{
${ }^{8}$ For an analogous analysis that relates to an autonomous act (local autonomy) vs. an autonomous person (global autonomy), see Christman (2015).
} 
circumstances and for different characters, (a) closedmindedness/selfblindness, (b) excessive defensiveness, (c) self-deception, (d) selfishness, (e) immorality, (f) excessive self-involvement/self-indulgence/selfabsorption, (g) excessive self-flattery/self-importance/self-promotion, (h) unjustified righteousness, (i) deepening of various cognitive biases, (j) denial of responsibility, and $(\mathrm{k})$ the precluding of possibilities for growth.

\section{Final comments}

In this paper I have provided a conceptual analysis of a broad and normatively content-neutral conception of justifying oneself. The conception I have defended balances out the predominantly negative conception of justifying oneself employed by most psychologists and reopens speculation as to the normative significance of possessing habits of justifying oneself.

A variety of theoretical and normative inquiries relating to this pervasive activity might be pursued. Do challenged commitments in fact need to be sincerely held in order for a response to be considered a case of justifying oneself? Can we draw a line between healthy and unhealthy engagement in justifying oneself in response to internal critique, and if so, how? Can we speak of ideal forms, or habits, of justifying oneself that cannot be fully unpacked in epistemological terms? If so, what do these look like, and how might education for that ideal be structured? Are habits of justifying oneself in fact reliably correlated with the positive and negative effects discussed above? Is it possible to make cateris paribus judgments about the general value of the habit of justifying oneself, or are all such judgments ultimately a matter for casuistry? I have not been concerned to provide answers to these or related questions. My goal has rather been to trace the basic conceptual contours of this important and little discussed phenomenon in the hope that it might aid in such inquiries. 


\section{REFERENCES}

Burkley, M. and H. Blanton. 2005. When Am I My Group? SelfEnhancement Versus Self-Justification Accounts of Perceived Prototypicality. Social Justice Research 18: 445-463.

Chigona, W., A. Chigona, B. Ngqokelela, and S. Mpofu. 2009. MXIT: Uses, Perceptions and Self-Justifications. Journal of Information, Information Technology, and Organizations 4: $1-16$.

Christman, J. 2014. Coping or Oppression: Autonomy and Adaptation to Circumstance. In Autonomy, Oppression, and Gender, eds. A. Veltman and M. Piper, 201-226. Oxford: Oxford University Press.

Christman, J. 2015. Autonomy in Moral and Political Philosophy. The Stanford Encyclopedia of Philosophy. Edited by Edward N. Zalta. Accessed May 30, 2017. http://plato.stanford.edu/ archives/spr2015/entries/autonomy-moral/.

D’Cruz, J. 2015. Rationalization as Performative Pretense. Philosophical Psychology, 28: 980-1000.

de Witt Huberts, J.C., C. Evers, and D. T. D. de Ridder. 2014. 'Because I Am Worth It': A Theoretical Framework and Empirical Review of a Justification-Based Account of Self-Regulation Failure. Personality and Social Psychology Review 18: 119-138.

Elster, J. 1989. Sour Grapes - Utilitarianism and the Genesis of Wants. In The Inner Citadel, ed. J. Christman, 170-188. New York: Oxford University Press.

Holland, R.W., R. M. Meertens, and M. van Vugt. 2002. Dissonance on the Road: Self-Esteem as a Moderator of Internal and External Self-Justification Strategies. Personality and Social Psychology Bulletin 28: 1713-1724.

Kivetz, R. and Y. Zheng. 2006. Determinants of Justification and SelfControl. Journal of Experimental Psychology: General 135: 572-587.

Lang 2002. Moral Clichés (or, How Not to Teach Ethics). Teaching Philosophy 25, no. 3 (Sept 2002): 247-250.

Lowell, J. 2012. Managers and Moral Dissonance: Self-Justification as a Big Threat to Ethical Management? Journal of Business Ethics 105: 17-25.

Mazar, N., O. Amir, and D. Ariely. 2008. The Dishonesty of Honest People: A Theory of Self-Concept Maintenance. Journal of Marketing Research 45: 633-644. 
Pittarello, A., M. Leib, T. Gordon-Hecker, and S. Shalvi. 2015. Justifications Shape Ethical Blind Spots. Psychological Science 26: 794-804.

Rescorla, M. 2009. Epistemic and Dialectical Regress. Australasian Journal of Philosophy 87: 43-60.

Scully, D., and J. Marolla. 1984. Convicted Rapists' Vocabulary of Motive: Excuses and Justifications. Social Problems 31: 530-544.

Shalvi, S., F. Gino, R. Barkan, and S. Ayal. 2015. Self-Serving Justifications: Doing Wrong and Feeling Moral. Current Directions in Psychological Science 24: 125-130.

Snyder, C.R. and R. L. Higgins. 1988. Excuses: Their Effective Role in the Negotiation of Reality. Psychological Bulletin 104: 23-35.

Stoljar, N. 2014. Autonomy and Adaptive Preference Formation. In Autonomy, Oppression, and Gender, eds. A. Veltman and M. Piper, 227-252. Oxford: Oxford University Press.

Wegner, R., A. Abbey, J. Pierce, S. E. Pegram, and J. Woerner. 2015. Sexual Assault Perpetrators' Justifications for Their Actions: Relations to Rape Supportive Attitudes, Incident Characteristics, and Future Perpetration. Violence Against Women 21: 1018-1037. 